\title{
Thermal Enhancement on Planetary Bodies and the Relevance of the Molar Mass Version of the Ideal Gas Law to the Null Hypothesis of Climate Change
}

\author{
Robert Ian Holmes \\ Science \& Engineering Faculty, Federation University, Ballarat, Australia
}

Email address:

robertholmes@students.federation.edu.au

To cite this article:

Robert Ian Holmes. Thermal Enhancement on Planetary Bodies and the Relevance of the Molar Mass Version of the Ideal Gas Law to the Null Hypothesis of Climate Change. Earth Sciences. Vol. 7, No. 3, 2018, pp. 107-123. doi: 10.11648/j.earth.20180703.13

Received: February 25, 2018; Accepted: March 14, 2018; Published: April 13, 2018

\begin{abstract}
Presented here is a simple and reliable method of accurately calculating the average near surface atmospheric temperature on all planetary bodies which possess a surface atmospheric pressure of over $0.69 \mathrm{kPa}$, by the use of the molar mass version of the ideal gas law. This method requires a gas constant and the near-surface averages of only three gas parameters; the atmospheric pressure, the atmospheric density and the mean molar mass. The accuracy of this method proves that all information on the effective plus the residual near-surface atmospheric temperature on planetary bodies with thick atmospheres, is automatically 'baked-in' to the three mentioned gas parameters. It is also known that whenever an atmospheric pressure exceeds $10 \mathrm{kPa}$, convection and other modes of energy transfer will totally dominate over radiative interactions in the transfer of energy, and that a rising thermal gradient always forms from that level. This rising thermal gradient continues down to the surface, and even below it if there is a depression or a mine-shaft present. This measured thermodynamic situation, coupled with other empirical science presented herein, mean that it is very likely that no one gas has an anomalous effect on atmospheric temperatures that is significantly more than any other gas. In short; there is unlikely to be any significant net warming from the greenhouse effect on any planetary body in the parts of atmospheres which are $>10 \mathrm{kPa}$. Instead, it is proposed that the residual temperature difference between the effective temperature and the measured near-surface temperature, is a thermal enhancement caused by gravitationally-induced adiabatic auto-compression, powered by convection. A new null hypothesis of global warming or climate change is therefore proposed and argued for; one which does not include any anomalous or net warming from greenhouse gases in the tropospheric atmospheres of any planetary body.
\end{abstract}

Keywords: Climate Sensitivity, Greenhouse Effect, Global Climate Change, Global Warming, Earth Temperature, Venus Temperature, Auto-Compression, Atmospheric Thermal Gradient

\section{Introduction}

The basis of this work was first published in 2017 [23]. Here is presented a more comprehensive version, which includes the following; a discussion on the causes of the late $20^{\text {th }}$ century warming, newly published papers, a reassessment of the accuracy of the temperature of Mars, a detailed discussion about Venus and an outline of the problems with the currently accepted 'null' hypothesis of climate. A new 'null' hypothesis of climate is advanced in this work, which excludes any significant anomalous warming effects arising from atmospheric greenhouse gases. It will be shown that any anomalous warming effects of greenhouse gases (GHG) such as $\mathrm{CO}_{2}$, are likely subjected to a $100 \%$ rate of negative feedback in all troposphere's, and that this appears to be inherent to all planetary atmospheric systems. The fine detail of these feedbacks will not be outlined here, but the open nature of the atmosphere, coupled with the following thermodynamic, scientific and other arguments, indicate that this new null hypothesis of climate is needed and fully makes sense. The present 'null hypothesis' of climate assumes - without empirical evidence - that there is a tropospheric greenhouse effect (GHE); meaning an anomalous net warming from greenhouse gases like $\mathrm{CO}_{2}$. This effect supposedly causes significant net warming in the troposphere [24] - even though this hypothetical warming has 
never actually been empirically measured, quantified and then attributed to GHG in any published, peer-reviewed scientific study to date.

\subsection{Thermal Gradients Appear in All Atmospheres Above a Pressure of $10 \mathrm{kPa}$}

It is known that planetary bodies which have thick atmospheres, naturally set up a rising thermal gradient in that part of the atmosphere which is higher than a pressure of $10 \mathrm{kPa}$, until that bodies' surface is reached [1] (Figure 1). Less well known is that this rising temperature gradient continues even below the surface [2] making it problematic to attribute this thermal gradient to the GHE. In this denser part of the atmosphere, the troposphere, convection and adiabatic autocompression effects rule over radiative or 'greenhouse' effects [21] in energy transfers, in the determination of atmospheric temperatures and in the formation of the thermal gradient. However, higher up in the atmosphere, once the atmospheric pressure drops below $10 \mathrm{kPa}$ then radiative effects dominate energy transfers. This is because the atmosphere there is too thin to initiate convection or any warming due to autocompression. Although the term 'auto-compression' may be unfamiliar to some, this can be seen as simply an engineering term for what meteorologists call the 'lapse rate' and astronomers call the 'Kelvin-Helmholtz' contraction. Under the latter, the contraction and compression of an inter-stellar molecular gas cloud under gravity, achieves such enormously high temperatures that nuclear fusion initiates, and a star is born [3]. Support for the idea of a permanent thermal gradient caused by the action of gravity on a thick atmosphere, in the presence of the solar flux comes from recent work by Nikolov \& Zeller [4].

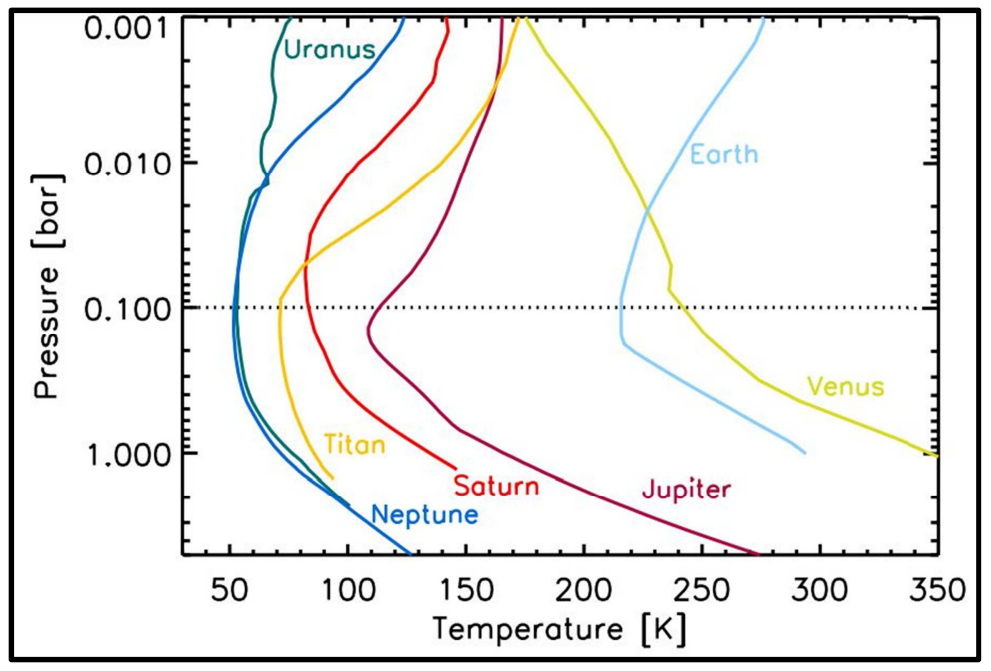

Figure 1. A thermal gradient appears in all planetary atmospheres $>10 \mathrm{kPa}[1]$.

Using this knowledge, an exacting yet simple method is introduced, which enables the average near-surface atmospheric temperature of any planetary body with an atmospheric pressure of over $10 \mathrm{kPa}$, to become easily and quickly calculated. A molar mass version of the ideal gas law is utilised (formulas 5 and 6), which consists of one fixed gas constant and three basic atmospheric gas parameters; the average near-surface atmospheric pressure, the average nearsurface atmospheric density and the mean molar mass of the near-surface atmosphere.

This formula proves itself here, to be not only more accurate than any other method heretofore used but is far simpler to calculate. It requires no input from parameters previously thought to be essential for the calculation of atmospheric temperatures, such as; solar insolation, albedo, greenhouse gas content, ocean circulation and cloud cover among many others. The reason these are not required, is because they, (and all others) are already automatically 'baked-in' to the three gas parameters mentioned. Note that although terms for insolation intensity and auto-compression are not used in the formula, it is proposed that these two are still what virtually determine an average near-surface planetary atmospheric temperature.

\subsection{Venus: The Planet Which Is Hard to Explain Using the Greenhouse Effect of $\mathrm{CO}_{2}$}

There has always been difficulty in explaining, or in formulating a simple method to satisfactorily explain or calculate the very high surface atmospheric temperature of the planet Venus using conventional mathematical means or by employing the greenhouse gas hypothesis. Here, the molar mass version of the ideal gas law will be used to simply and accurately determine the surface temperature of this planet, by the measurement of three gas parameters and the knowledge of one fixed gas constant.

Whatever hypothesis is used to explain the Earth's temperature, it must also take into account the universality of the physical laws of nature and of thermodynamics. For instance, it must explain how a universal atmospheric thermal gradient and enhancement [1] that is widely attributed to the action of a wholly above-surface GHE, can still continue on with its gradient unchanged, to below the surface level as it does in a mine-shaft [2]. And how this same gradient/enhancement appears in atmospheres with 
virtually no greenhouse gases present. And must also explain how the temperature in the Venusian atmosphere, at the same pressure as the Earth's surface, relates exactly to the Earth's average surface temperature once the different levels of solar insolation [5] are taken into account - despite the large differences in atmospheric greenhouse gas content. The
Venusian lapse rate, perhaps surprisingly, is very similar to Earth's at $7.7 \mathrm{~K} / \mathrm{km}$ but extends much higher, to at least $50 \mathrm{~km}$ [6]. A little below that height at $49 \mathrm{~km}$ is where a pressure of $1 \mathrm{~atm}$ is to be found and is where a temperature of $\sim 340 \mathrm{~K}$ has been measured $[6,78]$ to prevail.

Table 1. Earth's average temperature at latm vs the Venusian temperature at the same pressure.

\begin{tabular}{lllll}
\hline Planet & Temperature 1atm & Relative Solar Insolation & Fourth Root & Comparison Temperature \\
\hline Earth & 288 Kelvin & 1.00 & 1.000 & 288 Kelvin \\
Venus & 340 Kelvin & 1.91 & 1.176 & 289 Kelvin \\
\hline
\end{tabular}

The temperature of a planetary body in space varies with the fourth-root of the power incident upon it, meaning that the temperature of Venus at 1atm (Tv) should be the fourthroot of 1.91 times the temperature on Earth at $1 \mathrm{~atm}(\mathrm{Te})$. Venus receives 1.91 times the solar insolation of Earth [5] (Table 1).

$$
\mathrm{Tv}=\sqrt[4]{1.91} \times \mathrm{Te}
$$

The temperature in the Venusian atmosphere from Venera's 8, 9, 10, 11 and 12 and from the Pioneer Sounder at 1atm, averages $\sim 340 \mathrm{~K}[58$ ] [59]. This average temperature, divided by the fourth-root of the insolation difference, results in $289 \mathrm{~K}$ - a value very close to Earth's average surface temperature at $1 \mathrm{~atm}$. Yet Venus has a $96.5 \%$ greenhouse gas atmosphere, compared to Earth's at just 2.5\% [53]. It's hard to imagine atmospheres with such a differing greenhouse gas content, yet there still remain very strong similarities in the lapse rate, in the rate of the thermal gradient and as seen here, in the relative insolation-adjusted temperatures at $1 \mathrm{~atm}$. These measurements, relationships and the similarity of the thermal gradients point strongly towards the existence of a universal physical law which governs planetary atmospheric temperatures - and one which does not take into account the relative greenhouse gas contents; instead, this law clearly operates as if GHG are not special.

It is now possible to solve for Venus at 1atm for density, thus;

$$
\begin{gathered}
\rho=\text { PM } / \text { RT } \\
\rho=101.3 \times 43.45 / 8.314 \times 340=1.556 \mathrm{~kg} / \mathrm{m}^{3}
\end{gathered}
$$

The density at $1 \mathrm{~atm}$, assuming the atmosphere remains well mixed at a height of $49 \mathrm{~km}$, calculates out at $1.556 \mathrm{~kg} / \mathrm{m}^{3}$. Here the pressure has been chosen, and almost certainly the molar mass remains the same as the surface, therefore this has isolated any changes in the only free parameter remaining; the density. The differences to Earth's surface parameters are now clear and are caused by the pressure of a heavy dense atmosphere, offset by a density increase mitigated by the higher insolation. The comparison result is a $50 \%$ rise in molar mass, which in isolation would translate into a strong warming from $288 \mathrm{~K}$ to $432 \mathrm{~K}$. But there is also a $27 \%$ rise in density over Earth at 1atm, which relates to considerable offsetting cooling, resulting in the final temperature of $340 \mathrm{~K}$. Revealed here is the advantage of choosing a familiar pressure to work from rather than the unfamiliar Venusian surface pressures. It can be seen that the measured temperature difference from $288 \mathrm{~K}$ to $340 \mathrm{~K}$ is directly related to the $50 \%$ higher molar mass of the atmosphere combined with the $27 \%$ higher insolationmoderated atmospheric density and very likely not to its enhanced greenhouse properties.

Looking at the surface parameters on Venus can also be instructive; again, there is the same 50\% increase over Earth in molar mass, which in isolation brings the initial base warming to $432 \mathrm{~K}$. Then there remains the (very familiar on Earth) battle between pressure and density, which finally determines temperature. Here pressure clearly wins out with a surface pressure that is $91 x$ Earth's, and density settles at $53 x$ Earth's. Do these numbers point to the end result of a 'runaway greenhouse effect', or to just what would be expected from gas thermodynamics? Taking into account all factors, the evidence suggests the latter. What very likely determines these final numbers is the relationship between the enormous mass of the Venusian atmosphere, the autocompression and the energy put into the upper atmosphere by the Sun. There are many reasons to conclude that there is no net warming from the Venusian $\mathrm{CO}_{2}$.

Of note is that very little or no direct solar insolation reaches the Venusian surface [58, 59], certainly no more than $10 \%$ of that which reaches the Earth's surface. In addition, the lowest several kilometres of the Venus atmosphere are not a gas, but a super-critical fluid. The critical pressure of $\mathrm{CO}_{2}$ is $7,380 \mathrm{kPa}$ and the critical temperature is $+30^{\circ} \mathrm{C}$, so the conditions on the near-surface of Venus dictate that the entire atmospheric surface layer, to a depth of approximately $\sim 4 \mathrm{~km}$ must be a super-critical fluid. Five problems can be readily identified with regard to the possibility that the GHE of $\mathrm{CO}_{2}$ is the cause of Venus's high surface temperatures, as is currently claimed by NASA, the IPCC and most mainstream climate scientists;

1) The first question that might be asked is; can a highly compressed and super-heated super-critical fluid that is more like an ocean than a gas, still possess the greenhouse properties of an ordinary atmospheric gas? This seems to be highly unlikely. However, it is true that fermions, (of which $\mathrm{CO}_{2}$ is made) when highly compressed, increase the width of their absorption/emission bands, (because the Pauli Exclusion Principle [72] prevents fermions from being in the same state and in the same place.) Whether this factor has 
affected the surface super-critical fluid sufficiently to create a gas-like GHE is unknown at present.

2) A second problem with regard to the GHE claim for Venus is that the atmosphere is very thick and is optically opaque - more like a thick soup than transparent like the Earth's atmosphere is. Measurements from the surface of Venus show that $<20 \mathrm{~W} / \mathrm{m}^{2}$ of direct short-wave solar insolation $[58,77]$ actually makes it to the surface of Venus to warm the surface for the up-welling infra-red radiation to be available to be captured by any possible atmospheric GHE. In fact, direct solar insolation can be neglected below a height of $60 \mathrm{~km}$, as virtually all direct solar radiation below that level is 'scattered' by the thick atmosphere. The flux of this scattered solar insolation was measured on the surface by six separate landers and appears to be very low [58] averaging $<<10 \%$ of the $2,644 \mathrm{~W} / \mathrm{m}^{2}$ TOA insolation flux. In contrast, Earth receives much more at $12 \%$ of its TOA insolation directly onto the surface $\left(161 \mathrm{~W} / \mathrm{m}^{2}\right.$ of $\left.1,366 \mathrm{~W} / \mathrm{m}^{2}\right)$ [74] and much more if scattered, and atmospheric and back-radiation are counted.

3) Third, Venus has a very slow rotation period, which makes the Venusian 'night' $\sim 58$ Earth-days long [75]. During this long night, measurements have been taken of the atmospheric and the surface temperatures, and they remain basically the same all through the long night just as they are during the long 58-day Venusian 'day'. The surface cools only very slightly from $\sim 737 \mathrm{~K}$ to $\sim 732 \mathrm{~K}$ during this very long night. A question might reasonably be asked here; "How can the GHE of $\mathrm{CO}_{2}$ be responsible for all this surface heat, by trapping upwelling longwave radiation, emitted from absorbed direct solar insolation and hence keeping the surface hot with re-emitted downwelling radiation, when little or no direct Sun arrives to the surface during the 'day' and when no Sun at all arrives during the 58-day long 'night'?"

4) Fourth, the very high albedo reduces Venus's access to solar insolation. Even though Venus's TOA insolation is $\sim 2 \mathrm{x}$ Earth's, the reflectivity of Venus is so high at $75 \%$ that this more than cancels out the higher TOA insolation. This means that although it is closer to the Sun, the Venusian atmosphere as a whole actually absorbs much less Solar warmth than Earth does; $(2,644 / 4) \times(1-0.75)=165 \mathrm{~W} / \mathrm{m}^{2}$ vs $(1,366 / 4) \times(1-0.29)$ $=242 \mathrm{~W} / \mathrm{m}^{2}$ for Earth. If Venus receives even less net solar radiation than the Earth does, how can it maintain a very much higher temperature profile in its atmosphere because of this radiation?

5) Fifth, although as might be expected because of its high density, the Venusian atmosphere moves only slowly at the surface $(<10 \mathrm{~km} / \mathrm{hr})$, it rotates very rapidly at $70 \mathrm{~km}$ in height, the cloud tops level, circling the planet every 4 days at speeds of up to $100 \mathrm{~m} / \mathrm{s}(360 \mathrm{~km} / \mathrm{hr})$ [76]. Why does the Venusian atmosphere rotate westwards at sixty times [73] the rotation speed of the planet, and what is the mechanism driving and maintaining it? Given that the atmosphere is open to space and can expand and contract, and is in constant motion like this, how is the GHE of $\mathrm{CO}_{2}$ affected? Could it be subjected to sufficient negative feedbacks to eliminate any net warming from it altogether?

The Venus atmosphere is so hot that it radiates at the rate of $15,000 \mathrm{~W} / \mathrm{m}^{2}$ down to the surface, [79] even though less than $20 \mathrm{~W} / \mathrm{m}^{2}$ of direct solar insolation actually reaches the surface. A conventional 'GHE' of the type described by the IPCC is not possible with these numbers. If it is not the GHE, then where does Venus get the vast amount of energy from to keep such a heavy, thick atmosphere in motion and so very hot? The answer proposed here is the same as for Earth; autocompression, adiabatic convection and the conversion of higher-level atmospheric potential energy to lower-level kinetic energy.

\subsection{Molar Mass Version of Ideal Gas Law Accurately Calculates Planetary Surface Temperatures}

A version of the ideal gas law may be used to more accurately determine surface temperatures of planets with thick atmospheres than the S-B black body law, [7] if a density term is added; and if $\mathrm{kg} / \mathrm{m}^{3}$ is used for density instead of $\mathrm{gms} / \mathrm{m}^{3}$, the volume term $\mathrm{V}$ can be dropped. This formula then may be known as the molar mass version of the ideal gas law (Formulas 5 or 6 ).

$$
\text { The ideal gas law is; } \mathrm{PV}=\mathrm{nRT}
$$

Convert to molar mass; $\mathrm{PV}=\mathrm{m} / \mathrm{M}$.RT

Convert to density; PM/RT $=\mathrm{m} / \mathrm{V}=\rho$

$$
\text { Drop the volume term; } \rho=\mathrm{P} /(\mathrm{R} . \mathrm{T} / \mathrm{M})
$$

$$
\text { Find for temperature; } \mathrm{T}=\frac{\mathrm{P}}{\left(\mathrm{R} \times \frac{\rho}{\mathrm{M}}\right)}
$$

$$
\mathrm{V}=\text { volume }
$$

$\mathrm{m}=$ mass

$\mathrm{n}=$ number of moles

$\mathrm{T}=$ near-surface atmospheric temperature in Kelvin

$\mathrm{P}=$ near-surface atmospheric pressure in $\mathrm{kPa}$

$\mathrm{R}=$ gas constant $\left(\mathrm{m}^{3}, \mathrm{kPa}\right.$, kelvin $\left.{ }^{-1}, \mathrm{~mol}^{-1}\right)=8.314$

$\rho=$ near-surface atmospheric density in $\mathrm{kg} / \mathrm{m}^{3}$

$\mathrm{M}=$ near-surface atmospheric mean molar mass $\left(\mathrm{gm} / \mathrm{mol}^{-1}\right)$

Alternatively, the molar mass version of the ideal gas law can be written thus;

$$
\mathrm{T}=\mathrm{PM} / \mathrm{R} \rho
$$

\section{Methodology Involves Calculating the Average Near-Surface Temperature of Planets}

Formula 5 is here used throughout: Using the properties of Venus, [8] 


$$
T=\frac{9200}{\left(8.314 \times \frac{65}{43.45}\right)}
$$

Venus calculated surface temperature $=739.7 \mathrm{~K}$

Using the properties of Earth from Wiki, [9]

$$
T=\frac{101.3}{\left(8.314 \times \frac{1.225}{28.97}\right)}
$$

Earth calculated surface temperature $=288.14 \mathrm{~K}$

Venus is calculated at $739.7 \mathrm{~K}$, which is given by NASA as $\sim 740 \mathrm{~K}$. Earth is calculated at $288 \mathrm{~K}$, currently its quoted by NASA [5] at $288 \mathrm{~K}$. It will be noted that the average temperature of the surface of Titan was measured by the Voyager 1, and by the Huygens lander [10] and was probably used as an input to find the surface density; (the independently-measured surface density on Titan could not be found in the literature). The $94 \mathrm{~K}$ will therefore come out of the below formula, since it is a rearrangement of formula 3. This could be seen as a circular argument. However, it is unlikely that if and when the density of Titan is directly measured, for instance by the use of a dasymeter or similar, it will be significantly different from the $5.25 \mathrm{~kg} / \mathrm{m}^{3}$ stated here.

Calculate for Titan, data [11];

$$
T=\frac{146.7}{\left(8.314 \times \frac{5.25}{28.0}\right)}
$$

Titan calculated surface temperature $=93.6 \mathrm{~K}$

Titan and Saturn share the same solar insolation, yet Titan is much colder ( $39 \mathrm{~K}$ colder) than Saturn, despite the moon having 8,000 times the concentration of the strong greenhouse gas methane in its atmosphere than Earth does, or more relevantly, 3 times the methane concentration than Saturn does. Saturn has no other significant GHG in its atmosphere. Titan is even colder at latm - which is the level the temperature is being measured on Saturn. Why is Titan so cold, despite all the greenhouse gas it possesses, and in spite of receiving just the same solar insolation that Saturn does? Its density; at surface, the density is 27 times that at 1atm on Saturn. Questions remain about where and how Titan got such a dense and thick atmosphere, - and how the small moon retains it. Also of interest is that as well as the $2.7 \%$ Methane content, Titan has a $97 \%$ Nitrogen atmosphere, a gas which has been claimed to take on some of the properties of a greenhouse gas at the temperatures prevailing on Titan [80]. And like Venus, Titan's atmosphere appears to be a 'superrotator' [81], meaning that the atmosphere rotates much faster than the planetary surface does. Could this rapid motion be the result of a negative feedback effect related to the almost $100 \%$ of 'greenhouse gases' which comprise the atmospheres of both planetary bodies?

Calculate for Earth's South Pole, data [12];

$$
T=\frac{68.13}{\left(8.314 \times \frac{1.06}{28.97}\right)}
$$

Earth's South Pole average calculated temperature $=224 \mathrm{~K}$ $\left(-49^{\circ} \mathrm{C}\right)$

It's clear from these figures at the South Pole, that the low temperature comes mainly from the low pressure.

Calculate for Mars [13];

$$
T=\frac{0.69}{\left(8.314 \times \frac{0.02}{43.34}\right)} T=\frac{0.9}{\left(8.314 \times \frac{0.02}{43.34}\right)}
$$

Mars calculated surface temperature $=180 \mathrm{~K}$ to $234 \mathrm{~K}$

The average temperature on Mars is reported as either 210K [13] or 191K [4]. As suspected from other work [1] [4] this method of temperature calculation is tricky for Mars, due to the very low and highly variable atmospheric pressure. Pressures were measured [60] at the Viking 1 landing site and varied between $0.69 \mathrm{kPa}$ and $0.9 \mathrm{kPa}$, according to the season.

It is noted that it is only in atmospheres with a pressure of over $10 \mathrm{kPa}$ that strong convection and a troposphere/tropopause is formed, with its associated thermal gradient. Nevertheless, the formula still provides a useful range of surface temperature by the use of these lower pressures, which in fact extend evenly across the measured actual. For Mars, the mid-point between the summer and the winter pressures is used, which results in a calculated temperature of $207 \mathrm{~K}$, compared to the measured $210 \mathrm{~K}$.

The gas giants will now be assessed; note that these planets do not have a defined surface like the terrestrial planets have, so here they are given a 'surface' by using the Earth's surface pressure of $101.3 \mathrm{kPa}$ (1 $\mathrm{atm}$ ) as a level to use for this calculation.

Calculate for Jupiter [5];

$$
T=\frac{101.3}{\left(8.314 \times \frac{0.16}{2.2}\right)}
$$

Jupiter calculated temperature at $1 \mathrm{~atm}$ of pressure $=167 \mathrm{~K}$ Calculate for Saturn [5];

$$
T=\frac{101.3}{\left(8.314 \times \frac{0.19}{2.07}\right)}
$$

Saturn calculated temperature at $1 \mathrm{~atm}$ of pressure $=$ $132.8 \mathrm{~K}$

Calculate for Uranus [5];

$$
T=\frac{101.3}{\left(8.314 \times \frac{0.420}{2.64}\right)}
$$

Uranus calculated temperature at $1 \mathrm{~atm}$ of pressure $=76.6 \mathrm{~K}$ Calculate for Neptune [5];

$$
T=\frac{101.3}{\left(8.314 \times \frac{0.450}{2.53}\right)} T=\frac{101.3}{\left(8.314 \times \frac{0.450}{2.69}\right)}
$$

For Neptune, NASA supplies two values for mean molar mass; 2.53 and 2.69, this necessitated two separate calculations to give a high and a low of calculated 
temperatures, as was done for Mars. Neptune's calculated temperature at $1 \mathrm{~atm}$ gives a range of $68.5 \mathrm{~K}$ to $72.8 \mathrm{~K}$. The temperature on Neptune at $1 \mathrm{~atm}$ of pressure is measured at $72 \mathrm{~K}$; this lies quite handily between the two calculated temperatures. The calculated and actual average 'surface' temperatures of the eight planetary bodies are compared in Table 2, along with the errors.

Table 2. Comparison of calculated and actual average 'surface' temperatures.

\begin{tabular}{|c|c|c|c|}
\hline Planetary body & Calculated temperature Kelvin & Actual temperature Kelvin & Error \\
\hline Venus & 739.7 & 740 & $0.04 \%$ \\
\hline Earth & 288.14 & 288 & $0.00 \%$ \\
\hline South Pole of Earth & 224 & 224.5 & $0.20 \%$ \\
\hline Mars (low pressure) & 180 to 234 averages 207 & 210 & $1.40 \%$ \\
\hline Jupiter & 167 & 165 & $1.20 \%$ \\
\hline Saturn & 132.8 & 134 & $0.89 \%$ \\
\hline Titan & 93.6 & 94 & $0.42 \%$ \\
\hline Neptune & 68.5 to 72.8 averages 70.7 & 72 & $1.90 \%$ \\
\hline
\end{tabular}

\subsection{Explanation of the New' 'Null' Hypothesis of Climate Change Proposed Herein}

The existing null hypothesis of climate change simply assumes that there exists a $33^{\circ} \mathrm{C}$ 'residual' warming effect [66], which in turn is assumed to be $100 \%$ produced by GHG in the lower troposphere [24]. More assumptions are that once $\mathrm{CO}_{2}$ is emitted by humans to the atmosphere, it remains there for 'hundreds of years' [24]; another assumption is that the ice core record for $\mathrm{CO}_{2}$ is correct (and not the plant stomata record) and therefore that the $\mathrm{CO}_{2}$ concentration in 1750 (the so-called pre-industrial level) was $280 \mathrm{ppmv}$, and a final assumption is that all of the increase from this assumed $280 \mathrm{ppm}$ to the measured present level is anthropogenic. It is proposed here that most or all of these assumptions are incorrect. The residence time for $\mathrm{CO}_{2}$ is first shown to be incorrect; it is in fact just $4 \mathrm{yr}[65,69,70,71]$.

The new 'null' hypothesis of climate change being put forward here, is that in the case of Earth, solar insolation provides the 'first' $\sim 255^{*}$ Kelvin - in accordance with the black body law [14]; this being the 'effective' or the 'base' level. And a gravitationally induced thermal gradient caused by auto-compression provides the 'other' $\sim 33 *$ Kelvin, termed the 'residual', to arrive at the known and measured average global temperature of $288 \mathrm{Kelvin}$. The 'residual' is not hypothesised to be provided by anomalous warming from greenhouse gases, because if it was, it would not make sense that the Venusian temperature at 1atm correlates exactly with Earth's temperature at the same pressure, when insolation differences are allowed for.

And the consistent thermal gradients seen across atmospheres and across all greenhouse levels above $10 \mathrm{kPa}$ would not make sense, and the evidence presented in support of the new null hypothesis as laid out in detail in section 3 would be violated. The result of the 'thought experiment' conducted in section 2.7-9 is also consistent with all these findings. If the new null hypothesis of natural climate change is to be violated, substantial and convincing empirical scientific evidence would need to be brought to bear; it would need to be in excess of that which has been presented in the literature to date.

* These figures are disputed by recent work [4] however this still would not change the conclusions here.

\subsection{What Temperature Is and a Discussion About Maxwell and Loschmidt's Ideas}

Temperature in a gas is a measure of the average kinetic energy of the particles in the gas. When atmospheric gas pressure exceeds $10 \mathrm{kPa}$, a temperature gradient is set up from that pressure level, [1] down to a planetary surface. This thermal gradient constitutes a thermal enhancement and is known and measured to continue even below the surface, if there is for example, a mine shaft. It is hypothesised here, that the cause of this thermal gradient is gravity-induced auto-compression, and that along with insolation is an essential part of the null hypothesis of climate. In general terms, the surface temperature sets up convective overturning of the troposphere, which is adiabatic through much of the convection cycle [2], and this combines with gravitationally induced atmospheric auto-compression to create the observed tropospheric thermal enhancement and its associated temperature gradient.

The origins of this thermal effect on gases go back to James Maxwell, who, in his 1872 book 'Theory of Heat' [15] demonstrated that the formation of the thermal gradient from the tropopause downwards is assisted by convection and more particularly, the increasing atmospheric pressure, which itself is a result of a combination of the Earth's gravitational field and the atmospheric density.

"In the convective equilibrium of temperature, the absolute temperature is proportional to the pressure.." James Maxwell [15].

The idea of a thermal gradient naturally forming in any column of gas in a gravitational field was first proposed in the 1860's by Loschmidt [16]. At the time, Maxwell thought that this idea violated the second law of thermodynamics, yet as has been shown here, derivations of Maxwell's own ideal gas law is an excellent predictor of temperatures - whenever an atmosphere is thick enough to be compressed in a gravitational field.

The controversy between Loschmidt on one side, with Maxwell and Boltzmann on the other, raged for some time and was finally experimentally tested in 2007, with the 
results published by Graeff [17] [56]. Graeff's experiments concluded that a gravitationally-induced temperature gradient does spontaneously develop in sealed columns of both air and water - the bottom of the column being warmer than the top. The theoretical amounts of warming according to Graeff should be $0.07 \mathrm{~K} / \mathrm{m}$ and $0.04 \mathrm{~K} / \mathrm{m}$ respectively. Graeff's experimental apparatus reported $0.07 \mathrm{~K} / \mathrm{m}$ and $0.05 \mathrm{~K} / \mathrm{m}-$ so basically confirming Loschmidt's predictions. The thermal gradient appeared, despite the reverse gradient being prevalent in the immediate environment of the experiment. Loschmidt originally said that the second law of thermodynamics needed to be re-stated to include the effects of gravitational fields on fluids.

More recent work by Levy [57] has thrown some doubt on Graeff's work that a static column of a Maxwellian gas (such as air) can spontaneously create a stable thermal gradient. However, Levy's work does show that a thermal gradient is always created when a convective current, driven be a heat source arises in a Maxwellian gas that is immersed in a gravitational field; which is the exact case in all of the planetary atmospheres examined here. Also revealed in the work, is the theoretical basis for another observation - that the rate of the thermal gradient is dependent on the average molar mass of the atmosphere; with a higher molar mass resulting in a stronger gradient. A gravity-induced thermal gradient due to adiabatic compression is also found in the deep ocean, commencing at 5,000m [57].

\subsection{Auto-Compression Is Well Known and Used Daily in Mining}

Auto-compression is well known in underground mining and is used by ventilation engineers to calculate how hot the mine air will get, so that they know how much cooling air to provide at each level. The effect of auto-compression can be calculated by the following relationship;

$$
\mathrm{Pe}=\mathrm{Ps} \exp (\mathrm{gH} / \mathrm{RT})
$$

Where;

$\mathrm{Pe}=$ absolute pressure at end of column $(\mathrm{kPa})$

Ps $=$ absolute pressure at start of column $(\mathrm{kPa})$

$\mathrm{g}=$ acceleration due to gravity $\left(\mathrm{m} / \mathrm{s}^{2}\right)$

$\mathrm{H}=$ vertical depth $(\mathrm{m})$

$\mathrm{R}=$ Standard Temperature (Kelvin)

$\mathrm{T}=$ Final Temperature (Kelvin)

As can be clearly seen, this effect primarily relies on pressure and gravity, which will be different for each planetary body.

\subsection{Mechanism Is Adiabatic}

Note that we are examining a largely adiabatic process during convection. When a gas parcel expands adiabatically, as it does when rising in a gravitational field, it does positive work - and the kinetic energy drops and so the temperature drops. However, when a gas parcel is compressed, as it is when it descends adiabatically in a gravitational field, then it does negative work, and its kinetic energy rises and so its temperature goes up. Why does the kinetic energy of the gas rise when descending? It's because some of its potential energy is converted to enthalpy, so producing an increase in pressure, specific internal energy and hence, temperature in accordance with the following equation;

$$
\mathrm{H}=\mathrm{PV}+\mathrm{U}
$$

Where;

$\mathrm{H}=$ enthalpy $(\mathrm{J} / \mathrm{kg})$

$\mathrm{P}=$ pressure $(\mathrm{Pa})$

$\mathrm{V}=$ specific volume $\left(\mathrm{m}^{3}\right)$

$\mathrm{U}=$ specific internal energy (kinetic energy)

\subsection{Discussion on Maxwell vs Arrhenius and the 'Greenhouse Effect'}

Work in this area of gas physics was detailed in the $19^{\text {th }}$ century. However, there is a strong difference between the work and the views of the researchers Maxwell and Arrhenius. Maxwell's work [15] shows that temperatures in the lower troposphere of Earth are primarily determined by convection and the atmospheric mass/pressure/gravity relationship. Arrhenius's later work [18] completely ignored this and determined that temperatures in the lower troposphere of Earth are caused by the radiative effects of greenhouse gases. There have been papers critical of Arrhenius's radiative effects ideas since 1909 [19]. Which idea is correct is critical to the present, since if Arrhenius is correct, then there should be some concern about $\mathrm{CO}_{2}$ emissions, if the climate sensitivity is high enough. But if Loschmidt's version of Maxwell's work is correct, then doubling $\mathrm{CO}_{2}$ will have no measurable effect on tropospheric atmospheric temperatures, and the climate sensitivity will be too low to be measurable.

What do atmospheric measurements actually show? Measurements [20] of the effects of more $\mathrm{CO}_{2}$ in the atmosphere appear to strongly support Maxwell's ideas. At pressures above $10 \mathrm{kPa}$, "the extra $\mathrm{CO}_{2}$ merely replaces water vapour" and little difference is seen in temperatures - but at pressures below $10 \mathrm{kPa}$ more $\mathrm{CO}_{2}$ is measured to cause strong cooling. One of the main problems with the Arrhenius view, is that radiative transfers are emphasised, and convection is virtually ignored as a mode of heat transfer. Yet later work shows that not more than $11 \%$ of heat transfer in the troposphere is actually carried by radiation [21]. Whether a small change in this already small percentage can cause significant net warming in an open atmosphere is highly debatable. A recent paper has supported the Arrhenius view somewhat by quantifying a small forcing due to increased atmospheric $\mathrm{CO}_{2}$ [22], however, there has been no confirmation of this in a follow-up paper. But there still remains a lack of any paper in the literature, which quantifies any warming that has been attributed to increasing atmospheric $\mathrm{CO}_{2}$ concentrations.

\subsection{The Accuracy, Implications and Limitations of Formulas 5 and 6}

It is apparent that this simple formula calculates the near 
'surface' temperatures of many planetary bodies in our Solar System very accurately (Figure 2). Specifically, all of those which have atmospheres thick enough to form a troposphere (i.e. possessing an atmospheric pressure of $>10 \mathrm{kPa}$ ). These are; Venus, Earth, Jupiter, Saturn, Titan, Uranus and Neptune. All calculated temperatures are within $1.2 \%$ of the NASA reported 'surface' temperature (Mars's temperature can also be predicted but is $<<10 \mathrm{kPa}$, which is too low for convection to occur). This accuracy is achieved without using the S-B black body law, or the need to include terms for such parameters as TSI levels, albedo, clouds, GHE or, for that matter, adiabatic auto-compression.

All that is required to be able to accurately calculate the average near-surface atmospheric temperature, is the relevant gas constant and the knowledge of the three variable gas parameters.

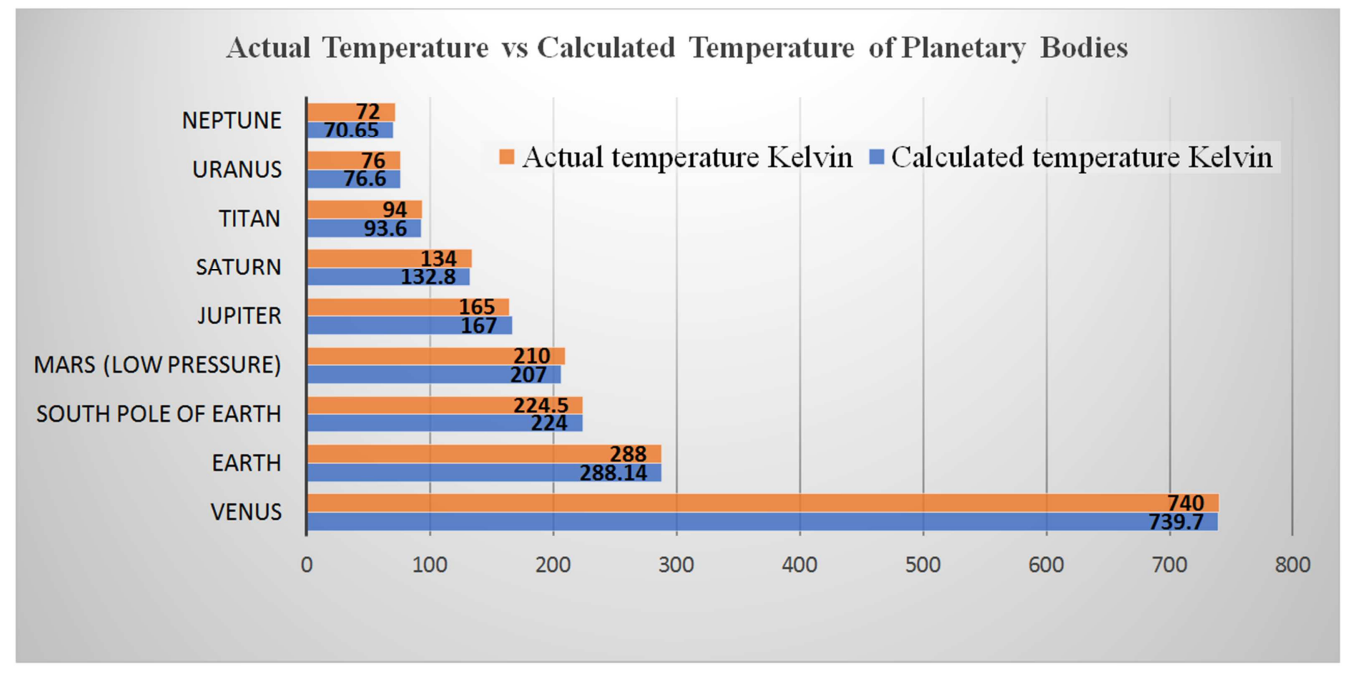

Figure 2. Actual temperature vs calculated temperature of 8 planetary bodies and the South Pole.

To be crystal clear about the limitations of the molar mass version of the ideal gas law; the nature of the formula means that it cannot in general be used to determine the cause of an atmospheric warming or cooling event. However, by isolating and examining changes to specific gas parameters, it may be possible to determine what is not causing a specific warming or cooling event - if the effect of the cause must result in a large anomalous change in a specific gas parameter or set of gas parameters.

\subsection{A Thought Experiment Involving Two Planets}

To more easily conceptualise and determine the source of the thermal gradients and the surface temperature enhancement which are known to exist on all planetary bodies with thick atmospheres [1], the use of a thought experiment is proposed.

Consider; two very Earth-like rocky planets with Earthlike atmospheres orbiting at the same distance (1 astronomical unit) from the Sun. We provide one with an atmosphere identical in every way to the present Earth's, containing $0.04 \% \mathrm{CO}_{2}$ by volume; let this planet be E1. Now the other planet E2, is going to be identical in every way to E1 except for a slight difference in the composition of the atmosphere. E2 will be identical to E1's atmosphere - but with one important difference; it will contain twice the concentration of $\mathrm{CO}_{2}$ at $0.08 \%$ by volume.

Clearly the existing greenhouse gas hypothesis, and the existing null hypothesis predicts that E2 should have a significantly higher $(\sim 3 \mathrm{~K})$ surface temperature than E1, because of its extra $0.04 \%$ of the greenhouse gas $\mathrm{CO}_{2}$ [24].
This IPCC reports' view is of a climate sensitivity at this level, this is also backed by the ' $97 \%$ consensus' [67]. Conversely, the new null hypothesis as presented here, predicts that both planets will have virtually identical temperatures. The dilemma is; how to determine which null hypothesis is correct? This puzzle appears to be solvable in the following manner.

How could a simple formula such as formula 5, which contains no reference to the percentage of $\mathrm{GHG}$ in an atmosphere, accurately predict the temperature of a planet with a very specific percentage of GHG, such as planet E2? Perhaps it would be informative to be aware of the wide variation in the atmospheres of other planetary bodies - some with up to $96 \%$ GHG in their atmospheres (Venus, Titan) and some others with virtually none (Jupiter, Saturn). A simple formula with no reference to GHG in it would not be expected to accurately predict the average atmospheric temperature of eight such widely differing planetary atmospheres, by the measurement of just three common planetary gas parameters.

And yet it does (Table 2, Figure 2).

The only way that is possible, if the greenhouse gas hypothesis is correct and these gases are special and cause strong warming, is that changes in the greenhouse gases' percentage in an atmosphere must alter the pressure and/or density anomalously; - in such a way as to make formulae 5 fit.

\subsection{The Search for an Anomalous Change in the Gas Parameters*}

If these two planets have almost the same 
pressure/density/molar mass, and hence virtually the same temperature, then the extra $0.04 \%$ of $\mathrm{CO}_{2}$ must have had almost no anomalous warming effect.

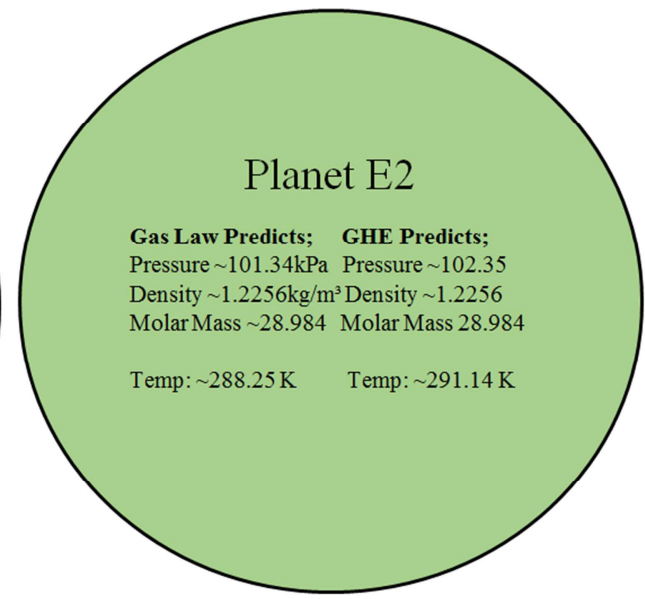

Figure 3. The present Earth (E1) is compared to a possible future Earth with a doubled $\mathrm{CO}_{2}$ (E2).

*Postulate; the molar mass version of the ideal gas law is correct.

1) For planet $\mathrm{E} 2$ to become $3^{\circ} \mathrm{C}$ warmer than $\mathrm{E} 1$, as is claimed by the IPCC, the extra $\mathrm{CO}_{2}$ must change one or more of the three gas parameters very significantly and anomalously - i.e. there has to be a large and an anomalous effect on one or more of these three gas parameters.

2) If the presence of the extra $\mathrm{CO}_{2}$ does not change one or more of the three gas parameters very significantly and hence anomalously, then the greenhouse gas hypothesis and the current null hypothesis must be incorrect and are invalidated.

3) This can be regarded as a test of the here-presented hypothesis that the present null hypothesis of climate change is incorrect and needs to be changed to one in which there is no net anomalous warming from GHG such as $\mathrm{CO}_{2}$.

\subsection{Assessing Whether an Anomalous Warming from a Doubling of $\mathrm{CO}_{2}$ Exists on Planet E2}

Scenario 1: When the reality with regards to the equivalence of the temperatures of Earth and Venus at the same pressure is taken into account (see section 1.2). A reasonable expectation would be that a $0.04 \%$ increase in atmospheric $\mathrm{CO}_{2}$, which is a relatively heavy gas, could be expected to result in the following approximate atmospheric changes in the three gas parameters;

Pressure: an increase of $0.04 \%$

Density: an increase of $0.05 \%$

Molar Mass: an increase of $0.05 \%$

Calculate using formula 5 a doubling of $\mathrm{CO}_{2}$ from the current level of $0.04 \%$;

$$
T=\frac{101.34}{\left(8.314 \times \frac{1.2256}{28.984}\right)}
$$

Calculated temperature after doubling of $\mathrm{CO}_{2}$ to $0.08 \% \approx$

\section{$288.25 \mathrm{~K}$}

'Reasonable Expectation' equilibrium climate sensitivity to $\mathrm{CO}_{2} \approx 288.25-288.14 \approx+0.11 \mathrm{~K}$

Under this circumstance, the climate sensitivity would in fact be extremely small and difficult to estimate exactly, but would be of the order $+0.11^{\circ} \mathrm{C}$. That is, twenty-seven times smaller than the stated 'likely' climate sensitivity of $3^{\circ} \mathrm{C}$ cited as the 'median' in the IPCC's reports [24]. This reasonable expectation of climate sensitivity to $\mathrm{CO}_{2}$ of $+0.11^{\circ} \mathrm{C}$ is so low that it would be impossible to detect or measure in the real atmosphere, even before any allowance is made for the consumption of atmospheric $\mathrm{O}_{2}$. But that small number would likely be a maximum change, because if fossil fuels are burned to create the emitted $\mathrm{CO}_{2}$ then atmospheric $\mathrm{O}_{2}$ will also be consumed, reducing that gas in the atmosphere - and offsetting much of any net temperature change that is generated by the extra $\mathrm{CO}_{2}$, reducing the climate sensitivity further.

Scenario 2: The alternative scenario is that $\mathrm{CO}_{2}$ possesses the same net atmospheric warming properties ascribed to it by the IPCC and most mainstream climate scientists. In this case, E2 would have to become $\sim 3^{\circ} \mathrm{C}$ warmer than $\mathrm{E} 1$, at equilibrium [24]. What would need to change in the parameters from scenario 1 - and by how much? And are these changes reasonable / possible? First, there could not be a change in the average molar mass, since the molar mass of all the atmospheric constituents are known fully and are known to always be well-mixed. This must remain at 28.984 . Therefore, by elimination, the entire $3^{\circ} \mathrm{C}$ of warming has to come from an anomalous and significant change in either the pressure, or the density, or both.

It is known from the formula, that when isolated, only a decrease in density can cause a warming; an increase will cause cooling. Similarly, when isolated, only an increase in pressure causes warming; a decrease causes cooling. And so here is a situation where a heavy gas is being added to the atmosphere; thus one logically expected outcome may be a higher atmospheric pressure, and so a higher temperature - and yet a 
higher pressure and a heavy gas would also surely indicate a greater density, - and so a counter-balancing lowering of temperature! This is a conundrum. How can this be resolved? Perhaps the pressure and density should be taken separately, to assist in clarifying the extent of the GHG anomaly problem.

If the $3{ }^{\circ} \mathrm{C}$ of warming is not thought to be even partly a result of density decreasing (which seems logical when a heavy gas is being introduced) then what increase in pressure would be required to explain all of the temperature change, if density were to be held static? This scenario is shown in E2, Figure 3.

Pressure: an increase of $1.00 \%$ due to greenhouse warming

Density: no anomalous change assumed

Molar Mass: no anomalous change possible

Calculate for a doubling of $\mathrm{CO}_{2}$ from the current level of $0.04 \%$ (by volume);

$$
T=\frac{102.35}{\left(8.314 \times \frac{1.2256}{28.984}\right)}
$$

Calculated temperature after doubling of $\mathrm{CO}_{2}$ to $0.08 \% \approx$ 291.14K

To reach the required temperature here, the pressure would have to increase anomalously by $1.00 \%$. How likely is it that the action of $0.04 \%$ more $\mathrm{CO}_{2}$ increases the pressure at equilibrium by twenty-five times through the GHE, over what would be expected from its physical presence alone? And this has to be seen as a minimum, because if the pressure increases, why wouldn't the density also increase especially from this heavier gas? As has been seen, an increase in density causes cooling, which would then demand an even greater increase in pressure to offset it, and so on.

If the causative parameters are reversed, and the pressure is held stable, then density would have to reduce anomalously in order to reach the required $3^{\circ} \mathrm{C}$ of warming. In this case;

Pressure: no anomalous change assumed

Density: a decrease of $0.91 \%$ due to greenhouse warming

Molar Mass: no anomalous change possible

Calculate for a doubling of $\mathrm{CO}_{2}$ from the current level of $0.04 \%$ (by volume);

$$
T=\frac{101.34}{\left(8.314 \times \frac{1.2140}{28.984}\right)}
$$

Calculated temperature after doubling of $\mathrm{CO}_{2}$ to $0.08 \% \approx$ 291.14K

The change in density required, if the pressure remained stable, would be a fall of $0.91 \%$. This represents an anomalous change of twenty-three times that which the percentage change in atmospheric gas alone would logically indicate. Again, if the pressure fell as well, then the required fall in density would have to be even greater to compensate. While still large, the smallest individual anomalous changes required would be if the pressure rose and simultaneously, density fell by a similar percentage. Logically, this combination may be the unlikeliest of these three possibilities. A possible worked example is provided here;

$$
T=\frac{101.85}{\left(8.314 \times \frac{1.2197}{28.984}\right)}
$$

Calculated temperature after doubling of $\mathrm{CO}_{2}$ to $0.08 \% \approx$ $291.16 \mathrm{~K}$

This scenario requires an anomalous change of $0.45 \%$ to pressure, combined with an anomalous change of $0.43 \%$ to density. These are eleven times and nine times respectively, the changes that would reasonably be expected. Evidence of anomalous changes due to the presence of GHG of this magnitude are not obvious in the gas data from any of the other planets, i.e. Venus, Titan. There doesn't appear to be any particular class of gases which cause very significant anomalous changes in any of the gas parameters. This result is not surprising, since the ideal gas law, in all of its varieties, makes no distinction between classes of gases based on their radiative absorption properties. Consistent with this view is that strong negative feedbacks are evident in the climate system of Earth, and that there are convincing natural explanations for the recent period of global warming (see section 3 ).

\subsection{Why the Ideal Gas Law Directly Conflicts with the Greenhouse Gas Hypothesis}

It is known that the ideal gas law does not differentiate between gases, and so its derivative, the molar mass version of the ideal gas law cannot either. This fact brings the derivative into direct conflict with the greenhouse gas hypothesis and the current, widely-accepted null hypothesis of climate change. Both of these hypotheses have at their core, a clear division between gases - those which cause atmospheric warming and those which do not. It has been shown that a gas which causes anomalous warming must also cause anomalous changes to pressure or density or both. Yet this violates the equivalence of gases which is fundamental to the ideal gas law. Therefore, either the ideal gas law is correct, or the greenhouse gas hypothesis of anomalous warming is correct; both cannot be correct.

A final proof that there can be no anomalous gas parameter changes due to 'greenhouse gases' is that it would be theoretically possible to change the pressure / density / molar mass in exactly the same way numerically - by using nongreenhouse gases to reach the same parameter results - and the same predicted planetary temperature. Only one combination of gases is permissible to reach the same parameter numbers. Therefore, the greenhouse gas hypothesis and the null hypothesis must be incorrect.

\section{Detailed Discussion on the Reasons for the Late $20^{\text {th }}$ Century Warming}

What was briefly outlined in previous work [23] and is being more comprehensively detailed in this work essentially for the first time, is the true scientific basis of the correct null hypothesis for climate change. Arguments have been aired in the climate literature over the last several 
decades that current global temperatures, and all present climate change is mostly unnatural, because climate change is now 98\% (according to the IPCC's reports and its 'relative forcings' chart in AR5) driven by man-made greenhouse gases, primarily $\mathrm{CO}_{2}$ [24]. Indeed, it has been claimed that a distinctively new and wholly man-made geological epoch has been entered, and that the Holocene now lies in the past [61]. This new epoch has even been named, it is called the Anthropocene [62].

But there is no solid scientific reason to suppose that natural climate change does not dominate the present, as it has always done in the past. For example; no scientific study has been published in the literature to date, which quantifies any atmospheric warming and attributes it to increasing manmade greenhouse gas emissions, primarily $\mathrm{CO}_{2}$. It is true that one paper exists [25] which has quantified a very small forcing $\left(0.2 \mathrm{~W} / \mathrm{m}^{2}\right.$ in the $2000-2010$ period) from increasing atmospheric $\mathrm{CO}_{2}$. It is by no means certain that this has or will translate into any net warming at all - furthermore, there is no solid and unchallenged evidence either, that the measured atmospheric increase in $\mathrm{CO}_{2}$ in the period 20002010 is all anthropogenic. Yet presently, the widely accepted 'null' hypothesis of climate includes significant tropospheric warming from greenhouse gases. But it is shown in this work, that if any warming effects might occur in the troposphere from increases in the greenhouse gas $\mathrm{CO}_{2}$, then they are almost certainly $100 \%$ eliminated by negative feedbacks in the climate system, and so will not manifest in the troposphere in the form of any net global warming.

Thermodynamics demands that if more $\mathrm{CO}_{2}$ were to start to 'create' an anomalous warming through forcing, then this must result in atmospheric expansion, because warmer air expands.
But this would increase potential energy at the expense of kinetic energy - so cooling the air again. The reverse would also happen; if there were less $\mathrm{CO}_{2}$, and this started to cause cooling, then the atmosphere must contract - so warming the air again through the conversion of potential to kinetic energy. Thus, the operation of gas laws coupled with natural convection are the primary means whereby forcing imbalances caused by greenhouse gases are eliminated. A second means of natural negative feedback to a $\mathrm{CO}_{2}$ forcing in the climate system arises through cloud production and albedo. More clouds are known to cause net cooling through a higher albedo [43]. The effect is not small, a mere $1 \%$ change in albedo being a greater forcing than all the anthropogenic forcing claimed by the IPCC from 1750 to date.

Opposing the lack of any empirical scientific evidence to support the claim that man-made GHG are now 'driving $98 \%$ of global warming and climate change', is an abundance of peer-reviewed, published material which supports the proposed new null hypothesis of natural climate change continuing right up to the present-day. Most claims about the anthropogenic nature of climate change focus on the period since 1950, when almost all anthropogenic emissions of GHG have occurred. During this period, data from other planets have also indicated that there has been unusually high solar activity in recent decades; Mars, [82, 83, 85]; Neptune, [84]; Pluto, [86, 87].

In particular, focus has generally been on the 1975-2000 warming, since a cooling occurred in the 1950-1975 period and a slower warming rate was seen in the 2000-2018 period than in the 1975-2000 period. These periods are well known and clearly defined in both atmospheric [26] and Oceanic data [63].

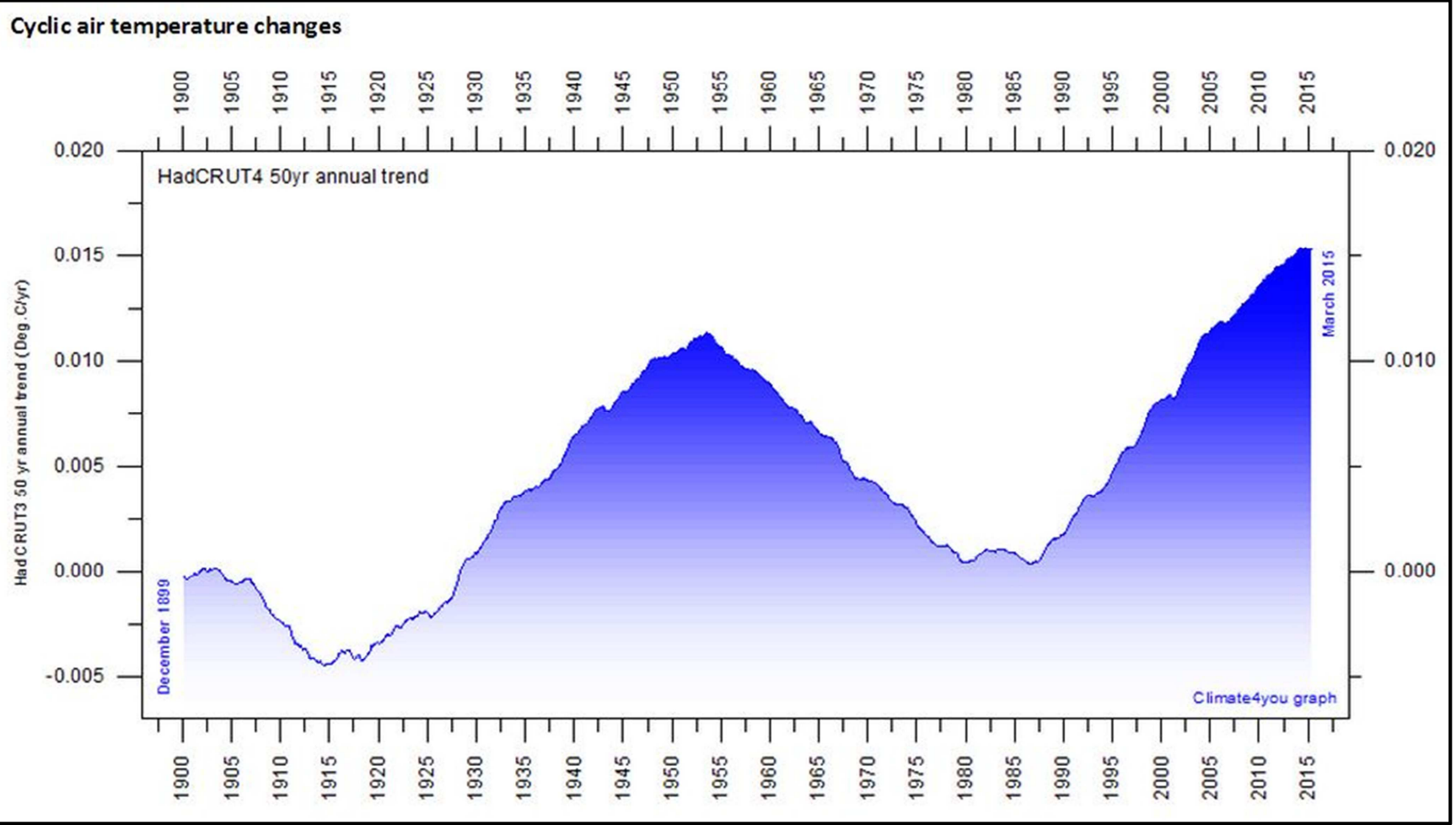

Figure 4. HadCRUT4 data converted to a 50yr trend [26]. 


\subsection{The Causes of the 1975-2000 Warming Period}

An examination of the HadCRUT4 monthly long-term global temperature record [88], reveals obvious cyclic peaks and troughs. The period covered is $1850-2018$ and peaks are seen in 1880, 1940 and 2000. When the data is converted into a $50 \mathrm{yr}$ trend a graph curve is obtained (Figure 4).

The conversion to a $50 \mathrm{yr}$ trend clarifies the existence of a strong $\sim 60 \mathrm{yr}$ cycle in the temperature data. (The process of conversion to this trend transposes the cycle $\sim 15 \mathrm{yr}$ towards the future). This climate cycle is the solar barycentre-related Yoshimura [27]; it is one among many others seen in the literature, most of which remain unacknowledged in any of the IPCC's reports.

This failure to include relevant science such as this into the reports strongly biases the conclusions arrived at within them. Clearly from this chart, the 1910-1940 warming and the 19752000 warming have much in common; yet the IPCC attributes the first to nature, and the second to man (because there were few anthropogenic $\mathrm{CO}_{2}$ emissions during the former, and rapidly accelerating emissions during the latter). The Yoshimura is in evidence throughout the climate system, and in proxy records, on all time-scales [30]. It also seems responsible for the current Arctic warming, which also occurred in the 1930's, and was just as warm then, if not warmer than it is now according the HadCRUT4 Arctic 70-90N data [28].

A decline of $6 \%$ in lower tropospheric tropical cloud cover $\left(15^{\circ} \mathrm{N}-15^{\circ} \mathrm{S}\right)$ occurred $1984-2000$ according to the international satellite cloud climatology project's data [29]. These years are contained well with the $1975-2000$ period of global warming, and an observed $0.4^{\circ} \mathrm{C}$ rise in global temperatures occurred over the same period. Scatter diagrams [55] of low cloud cover vs global surface air temperatures indicate that a $1 \%$ fall in low clouds equates to a $0.07^{\circ} \mathrm{C}$ rise in surface air temperatures - hence this change in cloudiness accounts for the entire observed rise in global temperatures during the 1975-2000 period, leaving no room for any effect from growing greenhouse gases.

\subsection{Known Climate Cycles Underpin Current Temperatures}

The current period of global warming started $\sim 1690$, when the little ice age bottomed out [33]. Hence, the modern period of global warming actually started centuries before manmade emissions could possibly have started to affect the energy balance. It is seen that there is an underlying increase in global temperatures in the HadCRUT4 Yoshimura influenced record (Figure 4). This underlying $20^{\text {th }}$ century rise, according to recent research on the way temperature data is processed, may not be due to an energy budget change at all [89] (Figure 7). This true nature of this underlying rise is almost certainly natural variability involving the slow inertial release of stored oceanic heat. The three recent warm peaks in the 61-year Yoshimura cycle; 1879, 1940 and 2001 are underpinned by other, medium-term climate cycles including the 248-yr de-Vries, the $1 \mathrm{kyr}$ Eddy and the $2.5 \mathrm{kyr}$ Bray (Figure 5) [31, 33]. These medium-term climate cycles have their origin in solar and planetary orbital interactions, planetary resonances [30] and barycentre motions [31, 32, 37] the detail of which are too extensive to include here.

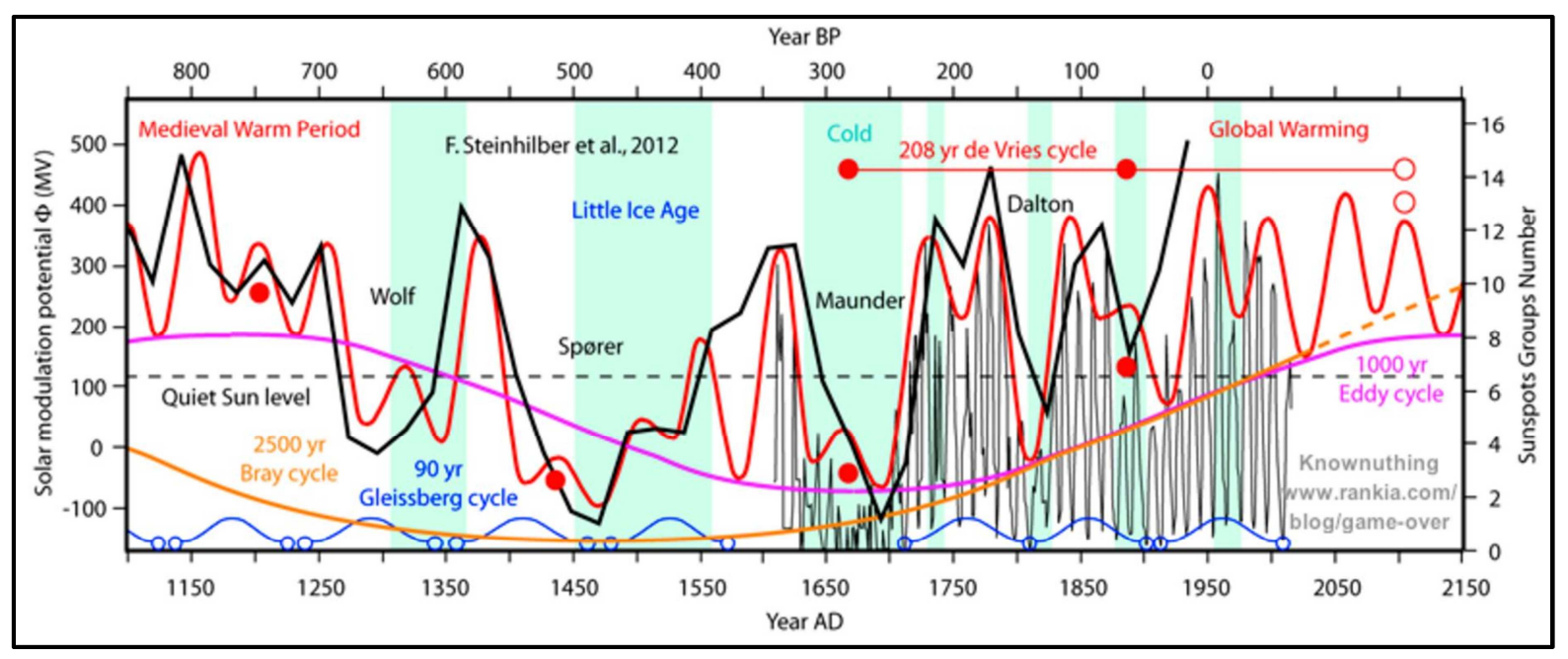

Figure 5. The climate cycles which underpin and caused the current period of global warming [33].

How the recent period of global warming (1690-present) occurred physically, is through a rapidly rising solar forcing caused by much higher solar activity [34, 35]. The solar activity in the latter half of the $20^{\text {th }}$ century was the highest for at least $4 \mathrm{kyr}$ [36] and perhaps as long as $11 \mathrm{kyr}$ [64]. This initial solar forcing is likely to have been amplified 4-8 times by feedback mechanisms [37-39] including an albedo-related one through cosmic rays and low clouds [40, 41]. Forbush decreases indicate that there is a strong solar-cloud link [42] though the cosmic ray flux affecting low cloud formation. Other modes of strong cloud feedbacks are also found in the climate system. The hemispheric differential in insolation intensity is known to increase by $15 \mathrm{~W} / \mathrm{m}^{2}$ at the surface over the period July-January every year due to eccentricity. Yet this large difference in forcing between the hemispheres during their respective summers has been measured to be 
virtually eliminated by strong negative cloud feedbacks, by affecting the relative hemispheric albedo [43]. For a comparison, the forcing from the increase in $\mathrm{CO}_{2}$ when adjusted to span the same time period [25] was measured to be only $0.01 \mathrm{~W} / \mathrm{m}^{2}$, which is 1,500 times $(15 / 0.01)$ smaller than just this one natural change in forcing. Perhaps this relationship is indicative of just why measuring any influence on the climate system from increasing atmospheric $\mathrm{CO}_{2}$ has proved to be so elusive.

The increase in total solar insolation (TSI) itself is thought to have been at least several times that reported in the IPCC reports for the 1750-2000 period according to several papers. TSI variations must have been at least 3 times larger [44, 45, $46,64]$ than is stated in the IPCC reports, otherwise the severe little ice age cooling centered on 1690 could not have been possible. Many other published papers [38, 39, 40, 41, 42] show that either the change in TSI since 1750 was much larger than reported by the IPCC, or there exist strong amplification mechanisms of that forcing, or (much more likely) both. The amplification mechanisms also mean that the 11-yr Schwabe related surface temperature changes are significant at $\sim 0.2^{\circ} \mathrm{C}$ [47] and these changes also increase with height to $\sim 0.8^{\circ} \mathrm{C}$ in the stratosphere [48].

More evidence supporting the new null hypothesis being applicable to the late $20^{\text {th }}$ century warming comes from a study of six European city's thermometer records and other climate records [49]. The six cities all cover at least the last $230 \mathrm{yr}$, and collectively display no significant overall trend. However, they do reveal at least five strong climate cycles, including the 248-yr De-Vries the 80-yr Gleissberg and the 61-yr Yoshimura respectively (Figure 6). The authors conclude that the cycles themselves explain all global temperature changes up until the time of publication, (2014) without any need for a contribution from anthropogenic greenhouse gases.

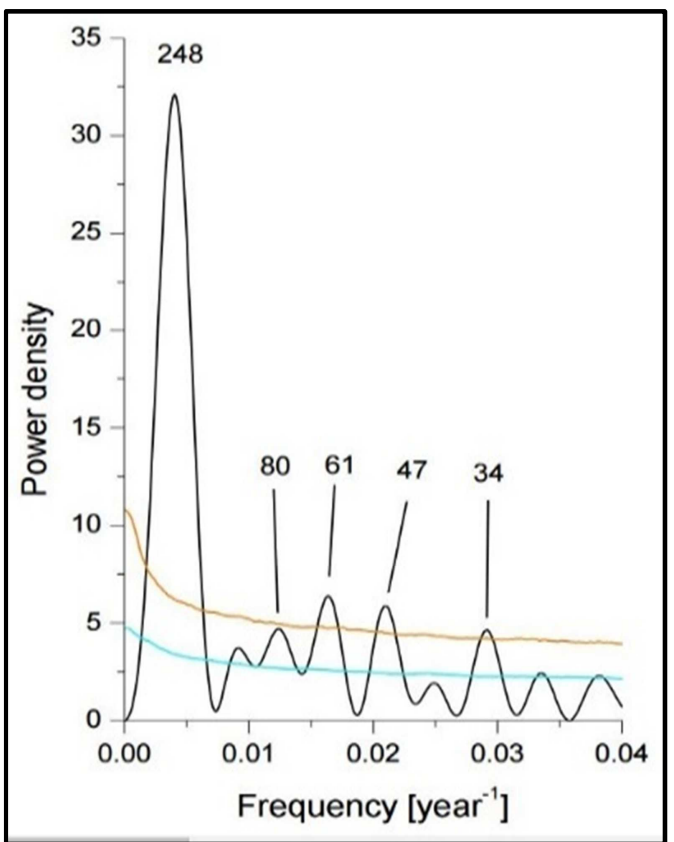

Figure 6. Five prominent climate cycles are revealed in the data from six European cities [49].

\section{Global Temperatures, 1900-2010}

433 Worldwide Valley/Ocean Air Sheltered Thermometer Stations (Scandinavia, C. Balkans Area, USA, C.Siberia, C China, Pakistan/NW India, Sahel, C South America, SE Australia, Southern Africa)

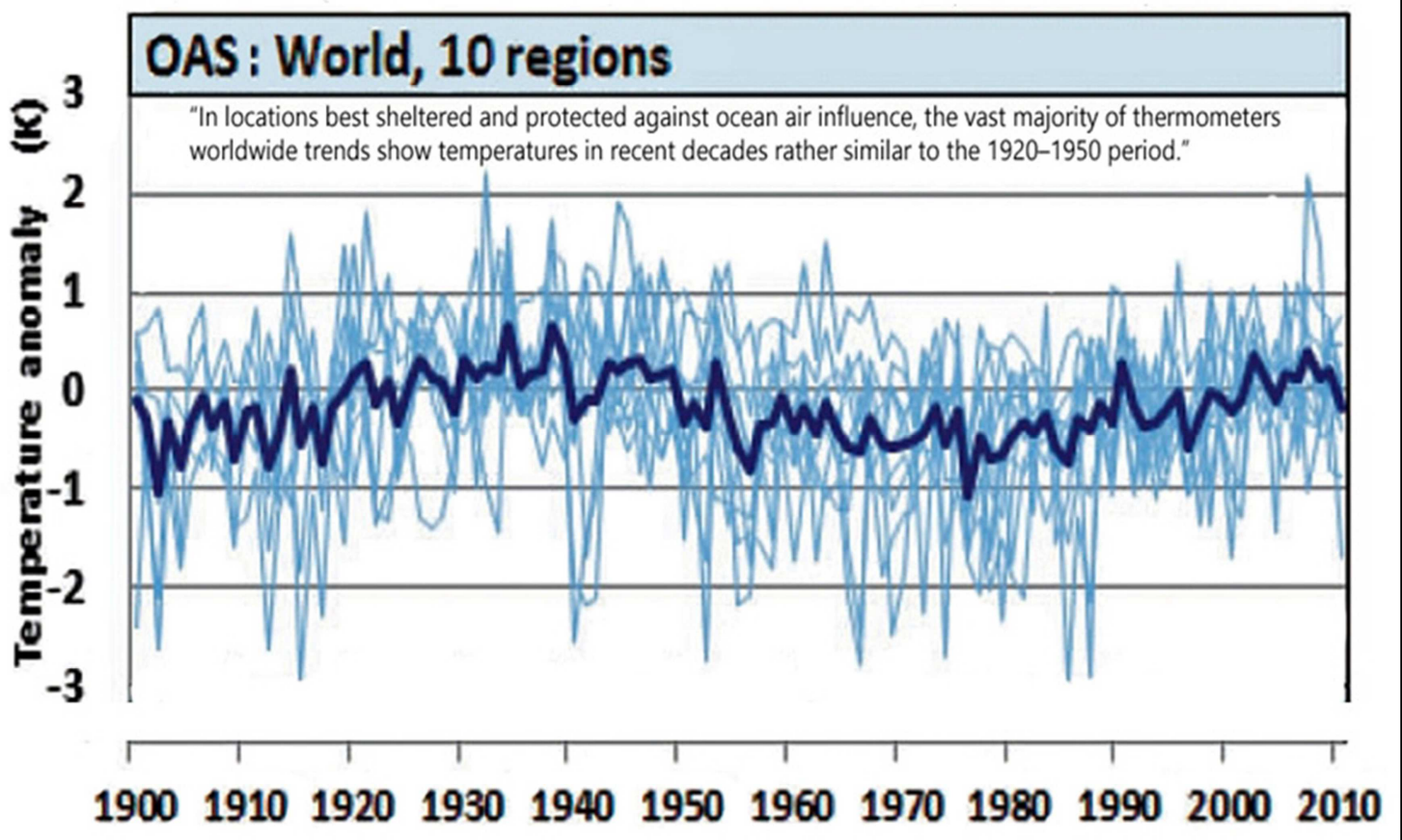

Figure 7. Sheltered thermometer stations on land show no warming; 1900-2010 data [89]. 
Further problems for the $\mathrm{CO}_{2}$ hypothesis arise if cyclic thermal inertia in the oceans are taken into account, as it has been in recent work by Lansner \& Pedersen [89] (Figure 7). The current period of global warming started several centuries ago; when the continuing and slow inertial oceanic warming from that process is discounted, and only raw temperature data from sheltered land areas all across the globe are examined, no warming trend is seen in the period 1900-2010 (Figure 7). Land areas sheltered from ocean winds currently display temperatures no higher than those prevailing in the 1920-1950 period.

\section{Probable Implications for the Climate Sensitivity to $\mathrm{CO}_{2}$}

Some reflection upon the simplicity and accuracy of the planetary results by the use of formula 5 , combined with knowledge of significant other factors such as the common planetary thermal enhancement / gradient; Venus \& Earth similarities at 1 bar; the supporting material on the 19752000 warming; the reasons why a new null hypothesis of climate is needed, and the above thought experiment should enable some probable implications of this work to be reached. These are that the residual near-surface atmospheric temperatures on planetary bodies with thick atmospheres are not mainly determined by the GHE, but instead are very likely caused by an effect from fluid dynamics, namely; autocompression. This leads directly to the conclusion that the climate sensitivity on Earth to, for example, a doubling of the atmospheric carbon dioxide concentration has to be not only operating instantaneously, but also must be extremely low. On balance, the evidence presented here clearly indicates that any net temperature change in the lower troposphere, caused by the addition of $0.04 \%$ of $\mathrm{CO}_{2}$, cannot be very different to the addition of a similar quantity of any other gas. In short; doubling atmospheric $\mathrm{CO}_{2}$ will not cause a measurable change in the temperature of the lower troposphere.

The reported figures for equilibrium climate sensitivity to $\mathrm{CO}_{2}$ in the literature have already been steadily reducing for decades, with recent papers pointing to a very low sensitivity of less than $1^{\circ} \mathrm{C} ;[50,51,52,68]$. A careful reading of these papers, (for example the most recent ones) clearly indicates that the $0.6^{\circ} \mathrm{C}$ cited, is in fact an absolute maximum. This present work, if not invalidated by subsequent work, clearly points to a climate sensitivity so low that it would not be possible to measure it in the real atmosphere.

To be clear, formulas $5 \& 6$ when considered in conjunction with the other material presented here, appears to rule out any possibility that the assumed $33^{\circ} \mathrm{C}$ of global warming from a 'GHE' of the type proposed by the IPCC in their reports can or does exist in the real atmosphere. The main reason is that the IPCC state in their reports that a $0.04 \%$ increase in atmospheric $\mathrm{CO}_{2}$, which represents a doubling from current levels, must result in an average global lower tropospheric near-surface temperature rise of $\sim 3^{\circ} \mathrm{C}$; (within a range of $1.5^{\circ} \mathrm{C}$ to $4.5^{\circ} \mathrm{C}$ ) $[24,54]$ and an even greater temperature rise at the poles and in the upper troposphere over the tropics. Atmospheric temperature rises have not been detected for $40 \mathrm{yr}$ over the Antarctic or in the upper troposphere over the tropics [90]. Despite considerable new information over recent years, the reported level of climate sensitivity to a doubling of atmospheric $\mathrm{CO}_{2}$, has not changed significantly from a median $3^{\circ} \mathrm{C}$ in the regular IPCC reports since 1990.

Any hypothetical large temperature rises caused by a doubling of $\mathrm{CO}_{2}$ must create a large anomalous change in one or both of two gas parameters (namely, pressure \& density) of which the molar mass version of the ideal gas law partly consists. There is no supporting scientific evidence for the existence of these large anomalous changes occurring in the atmosphere of Earth, or in the atmospheres of other planetary bodies such as Venus, as a result of a persistently higher percentages of greenhouse gases.

\section{Conclusion}

Here is presented a simple and accurate method of calculating the average near surface atmospheric temperature on all planetary bodies which possess a surface atmospheric pressure of over $0.69 \mathrm{kPa}$. This method requires knowledge of the gas constant and the measurement of only three atmospheric gas parameters; average near surface atmospheric pressure, average near surface atmospheric density and the mean molar mass of the atmosphere.

The formula used is the molar mass version of the ideal gas law. It is here demonstrated that the information contained in just these three gas parameters alone is an extremely accurate predictor of average near-surface atmospheric temperatures, in all atmospheres $>0.69 \mathrm{kPa}$. Therefore, all information on the effective plus the residual near-surface atmospheric temperature on planetary bodies with thick atmospheres, (effective meaning that predicted by S-B black body law, and residual being the difference between that and the measured actuality) must be automatically 'baked-in' to these three gas parameters.

A thought experiment involving two planets leads directly to the conclusion that a small change in any single atmospheric gas, not only has little effect on atmospheric temperatures, but has a very similar effect to the same percentage change in any other atmospheric gas. It is seen therefore, that as far as this formula goes, no one gas particularly affects atmospheric temperatures more than any other gas. Therefore, there can be no significant net 'greenhouse warming' caused by 'greenhouse gases' on Earth, or for that matter on any other planetary body. It is here hypothesised that the residual temperature differences, and the tropospheric thermal gradients / enhancements observed on all planetary bodies with thick atmospheres, are not caused by greenhouse gases. Instead, both are caused by an effect from thermodynamics, namely a gravity-induced adiabatic auto-compression of gases, the action of which is to 
enable heat transfer by continuously convecting all gases within the portions of all atmospheres which are $>10 \mathrm{kPa}$. The mechanism is as follows; rising parcels of air effectively 'store and hide' kinetic energy as potential energy; falling parcels of air effectively 'convert and reveal' potential energy as kinetic energy. The thermodynamics of this process is described in section 2.3 to 2.5 .

If more $\mathrm{CO}_{2}$ were to start to 'create' an anomalous warming through initiating a forcing, then the laws of thermodynamics demand that this must result in atmospheric expansion, because warmer air expands. But this would increase potential energy at the expense of kinetic energy as demanded by the above process - so cooling the air again. The reverse would also happen; if there were less $\mathrm{CO}_{2}$, and this started to cause cooling, then the atmosphere must contract - so warming the air again through the conversion of potential to kinetic energy. Thus, the operation of gas laws coupled with natural convection are the means whereby any forcing imbalances caused by greenhouse gases are eliminated.

Further to this, it is suggested that the 'null' hypothesis for climate, as presently understood, is invalid because it includes a very significant influence from an effect which has merely been assumed and has not been empirically detected, quantified or attributed and has not been shown to exist in the real atmosphere - namely, anomalous tropospheric warming from so-called 'greenhouse' gases. The present 'null' hypothesis for climate change needs to be immediately replaced with one which is based fully on empirical science, which adheres to the laws of thermodynamics and to the gas laws, and on atmospheric phenomena which have been measured, quantified and attributed.

Acknowledgement of non-specific Australian government support through;

"The Australian Government Research Training Program Scholarship".

\section{References}

[1] Robinson, T. D., \& Catling, D. C. (2014). Common 0.1 [thinsp] bar tropopause in thick atmospheres set by pressure-dependent infrared transparency. Nature Geoscience, 7(1), 12-15.

[2] McPherson, M. J. (2012). Subsurface ventilation and environmental engineering: Springer Science \& Business Media.

[3] Elmegreen, B. G., \& Elmegreen, D. M. (1986). Do density waves trigger star formation? The Astrophysical Journal, 311, 554-562.

[4] Nikolov, N., \& Zeller, K. (2017). New insights on the physical nature of the atmospheric greenhouse effect deduced from an empirical planetary temperature model. Environment Pollution and Climate Change, 1(2), 112.

[5] NASA fact sheet data on the planets, (2017). Accessed 11/2/18. https://nssdc.gsfc.nasa.gov/planetary/factsheet/

[6] Seiff, A. (1983). 11. Thermal Structure of the Atmosphere of Venus. Venus, 215.
[7] Stefan, J. (1879). On the relationship between thermal radiation and temperature. Bulletin from the sessions of the Vienna Academy of Sciences (Vienna, 1879), 79, 391-428.

[8] Zasova, L. V., Ignatiev, N., Khatuntsev, I., \& Linkin, V. (2007). Structure of the Venus atmosphere. Planetary and Space Science, 55(12), 1712-1728.

[9] Wikipedia, Properties of Earth's atmosphere, (2017). Accessed 11/2/18. https://en.wikipedia.org/wiki/Density_of_air

[10] Fulchignoni, M., Ferri, F., Angrilli, F., Ball, A. J., Bar-Nun, A., Barucci, M. A.,... \& Coradini,, M. (2005). In situ measurements of the physical characteristics of Titan's environment. Nature, 438(7069), 785-791.

[11] Lindal, G. F., Wood, G., Hotz, H., Sweetnam, D., Eshleman, V., \& Tyler, G. (1983). The atmosphere of Titan: An analysis of the Voyager 1 radio occultation measurements. Icarus, 53(2), 348-363.

[12] IceCube Wise; Wis/Mad Uni. Accessed 13/11/2017 http://icecube.wisc.edu/pole/weather

[13] Hess, S. L., Henry, R. M., Leovy, C. B., Ryan, J. A., \& Tillman, J. E. (1977). Meteorological results from the surface of Mars: Viking 1 and 2. Journal of Geophysical Research, 82(28), 4559-4574.

[14] NASA, black body curves Sun and Earth, (2017). Accessed 14/11/2017 https://Earthobser vatory.nasa.gov/Features/ArcticReflector/Images/black_body_ log_log_rt.gif

[15] Maxwell, J. C. (2012). Theory of heat: Courier Corporation.

[16] Flamm, D. (1997). Four papers by Loschmidt on the state of thermal equilibrium Pioneering Ideas for the Physical and Chemical Sciences (pp. 199-202): Springer.

[17] Graeff, R. W. (2007). Viewing The Controversy LoschmidtBoltzmann/Maxwell Through Macroscopic Measurements Of The Temperature Gradients In Vertical Columns Of Water. Preprint. Additional Results Are on the Web Page.

[18] Arrhenius, S. (1896). XXXI. On the influence of carbonic acid in the air upon the temperature of the ground. The London, Edinburgh, and Dublin Philosophical Magazine and Journal of Science, 41(251), 237-276.

[19] Wood, R. W. (1909). XXIV. Note on the Theory of the Greenhouse. The London, Edinburgh, and Dublin Philosophical Magazine and Journal of Science, 17(98), 319-320.

[20] Clough, S. A., Iacono, M. J., \& Moncet, J. L. (1992). Line by - line calculations of atmospheric fluxes and cooling rates: Application to water vapor. Journal of Geophysical Research: Atmospheres, 97(D14), 15761-15785.

[21] Khilyuk, L. (2003). Global warming: are we confusing cause and effect? Energy Sources, 25(4), 357-370.

[22] Feldman, D. R., Collins, W. D., Gero, P. J., Torn, M. S., Mlawer, E. J., \& Shippert, T. R. (2015). Observational determination of surface radiative forcing by $\mathrm{CO}_{2}$ from 2000 to 2010. Nature, 519(7543), 339-343.

[23] Holmes, R. I. (2017c). Molar Mass Version of the Ideal Gas Law Points to a Very Low Climate Sensitivity. Earth Sciences, 6(6), 157. 
[24] Team, C. W., Pachauri, R., \& Meyer, L. (2014). IPCC, 2014: Climate Change 2014: Synthesis Report. Contribution of Working Groups I. II and III to the Fifth Assessment Report of the Intergovernmental Panel on Climate Change. IPCC, Geneva, Switzerland, 151.

[25] Feldman, D. R., Collins, W. D., Gero, P. J., Torn, M. S., Mlawer, E. J., \& Shippert, T. R. (2015). Observational determination of surface radiative forcing by $\mathrm{CO}_{2}$ from 2000 to 2010. Nature, 519(7543), 339-343.

[26] Climate4you 50yr trend, (2018). Access 11/2/18 http://www.climate4you.com/images/HadCRUT4\%2050yr\%2 0AnnualitresendSinceDecember1899.gif

[27] Yoshimura, H. (1979). The solar-cycle period-amplitude relation as evidence of hysteresis of the solar-cycle nonlinear magnetic oscillation and the long-term $/ 55$ year/cyclic modulation. The Astrophysical Journal, 227, 1047-1058.

[28] http://www.climate4you.com/images/7090N\%20MonthlyAnomaly\%20Since1920.gif Accessed $11 / 2 / 2018$.

[29] https://isccp.giss.nasa.gov/products/onlineData.html Accessed $11 / 2 / 2018$.

[30] Semi, P. (2009). Orbital resonance and Solar cycles. arXiv preprint arXiv:0903.5009.

[31] Velasco, V., Mendoza, B., \& Valdes-Galicia, J. (2008). The 120-yrs solar cycle of the cosmogenic isotopes. Paper presented at the International Cosmic Ray Conference.

[32] Scafetta, N. (2014). The complex planetary synchronization structure of the solar system. arXiv preprint arXiv:1405.0193.

[33] Steinhilber, F., Abreu, J. A., Beer, J., Brunner, I., Christl, M., Fischer, H.,... McCracken, K. G. (2012). 9,400 years of cosmic radiation and solar activity from ice cores and tree rings. Proceedings of the National Academy of Sciences, 109(16), 5967-5971.

[34] Lüdecke, H.-J. (2011). Long-term instrumental and reconstructed temperature records contradict anthropogenic global warming. Energy \& Environment, 22(6), 723-745.

[35] Solanki, S. K., Usoskin, I. G., Kromer, B., Schüssler, M., \& Beer, J. (2004). Unusual activity of the Sun during recent decades compared to the previous 11,000 years. Nature, 431(7012), 1084-1087.

[36] Usoskin, I. G., Solanki, S., \& Kovaltsov, G. (2007). Grand minima and maxima of solar activity: new observational constraints. Astronomy \& Astrophysics, 471(1), 301-309.

[37] Shaviv, N. J. (2008). Using the oceans as a calorimeter to quantify the solar radiative forcing. Journal of Geophysical Research: Space Physics, 113(A11).

[38] Svensmark, H. (2007b). Cosmoclimatology: a new theory emerges. Astronomy \& Geophysics, 48(1), 1.18-11.24.

[39] Shaviv, N. J. (2005). On climate response to changes in the cosmic ray flux and radiative budget. Journal of Geophysical Research: Space Physics, 110(A8).

[40] Svensmark, H., Enghoff, M. B., \& Pedersen, J. O. P. (2013). Response of cloud condensation nuclei $(>50 \mathrm{~nm})$ to changes in ion-nucleation. Physics Letters A, 377(37), 2343-2347.

[41] Yu, F., \& Luo, G. (2014). Effect of solar variations on particle formation and cloud condensation nuclei. Environmental Research Letters, 9(4), 045004.

[42] Svensmark, H., Bondo, T., \& Svensmark, J. (2009). Cosmic ray decreases affect atmospheric aerosols and clouds. Geophysical Research Letters, 36(15).

[43] Stephens, G. L., O'Brien, D., Webster, P. J., Pilewski, P., Kato, S., \& Li, J.-1. (2015). The albedo of Earth. Reviews of Geophysics, 53(1), 141-163.

[44] Foukal, P., Fröhlich, C., Spruit, H., \& Wigley, T. M. L. (2006). Variations in solar luminosity and their effect on the Earth's climate. Nature, 443(7108), 161-166.

[45] Douglass, D. H., \& Clader, B. D. (2002). Climate sensitivity of the Earth to solar irradiance. Geophysical Research Letters, 29(16).

[46] Pulkkinen, T., Nevanlinna, H., Pulkkinen, P., \& Lockwood, M. (2001). The Sun-Earth connection in time scales from years to decades and centuries. Space Science Reviews, 95(1-2), 625-637.

[47] Camp, C. D., \& Tung, K. K. (2007). Surface warming by the solar cycle as revealed by the composite mean difference projection. Geophysical Research Letters, 34(14).

[48] White, W. B. (2006). Response of tropical global ocean temperature to the Sun's quasi - decadal UV radiative forcing of the stratosphere. Journal of Geophysical Research: Oceans, 111(C9).

[49] Lüdecke, H.-J., Hempelmann, A., \& Weiss, C. (2013). Multiperiodic climate dynamics: spectral analysis of long-term instrumental and proxy temperature records. Climate of the Past, 9(1), 447.

[50] Harde, H. (2014). Advanced Two-Layer Climate Model for the Assessment of Global Warming by $\mathrm{CO}_{2}$.

[51] Cederlöf, M. (2014). Using seasonal variations to estimate Earth's response to radiative forcing.

[52] Abbot, J., \& Marohasy, J. (2017). The application of machine learning for evaluating anthropogenic versus natural climate change. GeoResJ, 14, 36-46.

[53] http://ossfoundation.us/projects/environment/globalwarming/atmospheric-composition Accessed 11/2/2018.

[54] Allen, M. R., Barros, V. R., Broome, J., Cramer, W., Christ, R., Church, J. A.,... Dubash, N. K. (2014). IPCC Fifth Assessment Synthesis Report-Climate Change 2014 Synthesis Report.

[55] http://www.climate4you.com/images/TotalCloudCoverVersus GlobalSurfaceAirTemperature.gif accessed 13/2/2018.

[56] Graeff, R. W. (2002, November). Measuring the temperature distribution in gas columns. In AIP Conference Proceedings(Vol. 643, No. 1, pp. 225-230). AIP.

[57] Levy, G. S. (2016, June). Loschmidt's Temperature Gradient Paradox-A Quantum Mechanical Resolution. In 97th Annual Meeting of the American Association for the Advancement of Science, Limits to the Second Law of Thermodynamics, University of San Diego, San Diego, California (pp. 14-17).

[58] Moroz, V., Ekonomov, A., Moshkin, B., Revercomb, H., Sromovsky, L., Schofield, J., Tomasko, M. G. (1985). Solar and thermal radiation in the Venus atmosphere. Advances in Space Research, 5(11), 197-232. 
[59] Zasova, L., Ignatiev, N., Khatuntsev, I., \& Linkin, V. (2007). Structure of the Venus atmosphere. Planetary and Space Science, 55(12), 1712-1728.

[60] Lindal, G. F., Hotz, H. B., Sweetnam, D. N., Shippony, Z., Brenkle, J. P., Hartsell, G. V., \& Michael, W. H. (1979). Viking radio occultation measurements of the atmosphere and topography of Mars: Data acquired during 1 Martian year of tracking. Journal of Geophysical Research: Solid Earth, 84(B14), 8443-8456.

[61] Lewis, S. L., \& Maslin, M. A. (2015). Defining the anthropocene. Nature, 519(7542), 171.

[62] Zalasiewicz, J., Williams, M., Steffen, W. \& Crutzen, P (2010). The new world of the Anthropocene.

[63] Gouretski, V., Kennedy, J., Boyer, T., \& Köhl, A. (2012). Consistent near - surface ocean warming since 1900 in two largely independent observing networks. Geophysical Research Letters, 39(19).

[64] Yndestad, H., \& Solheim, J. E. (2017). The influence of solar system oscillation on the variability of the total solar irradiance. New Astronomy, 51, 135-152.

[65] Harde, H. (2017). Scrutinizing the carbon cycle and CO 2 residence time in the atmosphere. Global and Planetary Change, 152, 19-26.

[66] Lacis, A. A., Schmidt, G. A., Rind, D., \& Ruedy, R. A. (2010). Atmospheric CO2: Principal control knob governing Earth's temperature. Science, 330(6002), 356-359.

[67] Cook, J., Oreskes, N., Doran, P. T., Anderegg, W. R., Verheggen, B., Maibach, E. W.,... Green, S. A. (2016). Consensus on consensus: a synthesis of consensus estimates on human-caused global warming. Environmental Research Letters, 11(4), 048002.

[68] Lightfoot, H. D., \& Mamer, O. A. (2014). Calculation of atmospheric radiative forcing (Warming Effect) of carbon dioxide at any concentration. Energy \& Environment, 25(8), 1439-1454.

[69] Lepori, L., Bussolino, G., Matteoli, E., \& Spanedda, A. On the increase of fossil $\mathrm{CO} 2$ in the atmosphere.

[70] Segalstad, T. V. (1998). Carbon cycle modelling and the residence time of natural and anthropogenic atmospheric $\mathrm{CO}_{2}$. BATE, R.(Ed., 1998): Global Warming, 184-219.

[71] Quirk, T. (2009). Sources and sinks of carbon dioxide. Energy \& Environment, 20(1), 105-121.

[72] Pauli, W. (1988). Exclusion principle, Lorentz group and reflection of space-time and charge Wolfgang Pauli (pp. 459479): Springer.

[73] Hollingsworth, J., Young, R., Schubert, G., Covey, C., \& Grossman, A. (2007). A simple - physics global circulation model for Venus: Sensitivity assessments of atmospheric superrotation. Geophysical Research Letters, 34(5).

[74] Trenberth, K. E., Fasullo, J. T., \& Kiehl, J. (2009). Earth's global energy budget. Bulletin of the American Meteorological Society, 90(3), 311-323.
[75] Landis, G., Dyson, R., McGuire, M., Oleson, S., Schmidt, G., Grantier, J.,... Fincannon, J. (2011). Human Telerobotic Exploration of Venus: A Flexible Path Design Study. Paper presented at the 49th AIAA Aerospace Sciences Meeting including the New Horizons Forum and Aerospace Exposition.

[76] Svedhem, H., Titov, D. V., Taylor, F. W., \& Witasse, O. (2007). Venus as a more Earth-like planet. Nature, 450(7170), 629-632.

[77] Jelbring, H. (2003). The "Greenhouse Effect" as a Function of Atmospheric Mass. Energy \& Environment, 14(2), 351-356.

[78] Pätzold, M., Häusler, B., Bird, M. K., Tellmann, S., Mattei, R., Asmar, S. W.,... \& Tyler, G. L. (2007). The structure of Venus' middle atmosphere and ionosphere. Nature, 450(7170), 657.

[79] Crisp, D. (2007). Greenhouse Effect and Radiative Balance on Earth and Venus. Presentation to the Venus Exploration Assessment Group (VEXAG).

[80] Pierrehumbert, R. T. (2011, November). Infrared radiation and planetary temperature. In AIP Conference Proceedings (Vol. 1401, No. 1, pp. 232-244). AIP.

[81] Porco, C. C., Baker, E., Barbara, J., Beurle, K., Brahic, A., Burns, J. A.,... \& Denk, T. (2005). Imaging of Titan from the Cassini spacecraft. Nature, 434(7030), 159.

[82] Fenton, L., Geissler, P., \& Haberle, R. (2006). Global warming on Mars. Paper presented at the AGU Fall Meeting Abstracts.

[83] Pollack, J. B., Kasting, J. F., Richardson, S. M., \& Poliakoff, K. (1987). The case for a wet, warm climate on early Mars. Icarus, 71(2), 203-224.

[84] Sromovsky, L., Fry, P., Limaye, S., \& Baines, K. (2003). The nature of Neptune's increasing brightness: Evidence for a seasonal response. Icarus, 163(1), 256-261

[85] Ravilious, K. (2007). Mars melt hints at solar, not human, cause for warming, scientist says. National Geographic News. $\mathrm{http} / / /$ news. nationalgeogr.../55741367. html.

[86] Pasachoff, J. M., Souza, S. P., Babcock, B. A., Ticehurst, D. R., Elliot, J., Person, M., Tholen, D. J. (2005). The structure of Pluto's atmosphere from the 2002 August 21 stellar occultation. The Astronomical Journal, 129(3), 1718.

[87] Elliot, J. L., Person, M., Gulbis, A., Souza, S., Adams, E., Babcock, B.,... Pasachoff, J. (2007). Changes in Pluto's atmosphere: 1988-2006. The Astronomical Journal, 134(1), 1.

[88] Climate Research Unit data; https://crudata.uea.ac.uk/cru/data/temperature/HadCRUT4gl.dat Accessed 10/3/18.

[89] Lansner, F., \& Pedersen, J. O. P. (2017). Temperature trends with reduced impact of ocean air temperature.

[90] University of Alabama at Huntsville data from the Trios-N satellite $1979-2018$. https://www.nsstc.uah.edu/data/msu/t2lt/uahncdc.lt Accessed $10 / 3 / 2018$ 